Article

\title{
Spectroscopic and Electrochemical Studies of Imogolite and Fe-Modified Imogolite Nanotubes
}

\author{
Carmen Castro ${ }^{1}$, Nicolas Arancibia-Miranda ${ }^{1,2}$, Cristina Acuña-Rougier ${ }^{1}$, Mauricio Escudey ${ }^{1,2}$ \\ and Federico Tasca ${ }^{1, *}$ \\ 1 Department of Chemistry of Materials, University of Santiago of Chile, 9170022 Santiago, Chile; \\ carmen.castroc@usach.cl (C.C.); nicolas.arancibia@usach.cl (N.A.-M.); cristiacu@gmail.com (C.A.-R.); \\ mauricio.escudey@usach.cl (M.E.) \\ 2 Center for the Development of Nanoscience and Nanotechnology, CEDENNA, 9170022 Santiago, Chile \\ * Correspondence: federico.tasca@usach.cl; Tel.: +56-02-2718-1042
}

Academic Editor: Mo Song

Received: 27 November 2015; Accepted: 14 January 2016; Published: 2 February 2016

\begin{abstract}
Carbon nanotubes and other forms of carbon nanoparticles, as well as metal nanoparticles have been widely used in film electrochemistry because they allow for the immobilization of larger amounts of catalyst (either biological or inorganic) on the top of the modified electrodes. Nevertheless, those nanoparticles present high costs of synthesis and of separation and purification that hamper their employment. On the other hand, imogolites (Im), with the general formula $(\mathrm{OH})_{3} \mathrm{Al}_{2} \mathrm{O}_{3} \mathrm{SiOH}$, are naturally-occurring nanomaterials, which can be obtained from glassy volcanic ash soils and can also be synthesized at mild conditions. In this research paper, we characterize through spectroscopic techniques (i.e., fourier transform infrared spectroscopy (FTIR) spectroscopy, powder X-ray diffraction (XRD) and transmission electron microscopy (TEM)) synthetized Im and Fe-modified imogolite $(\operatorname{Im}(\mathrm{Fe}))$. Moreover, the $\operatorname{Im}$ and $\operatorname{Im}(\mathrm{Fe})$ were physically adsorbed on the top of a graphite electrode (GE) and were characterized electrochemically in the potential region ranging from -0.8 to $0.8 \mathrm{~V} v s$. the saturated calomel electrode (SCE). When the film of the $\operatorname{Im}$ or of the $\operatorname{Im}(\mathrm{Fe})$ was present on the top of the electrode, the intensity of the charging/discharging current increased two-fold, but no redox activity in the absence of $\mathrm{O}_{2}$ could be appreciated. To show that $\operatorname{Im}$ and $\operatorname{Im}(\mathrm{Fe})$ could be used as support for catalysts, iron phthalocyanine ( $\mathrm{FePc}$ ) was adsorbed on the top of the $\operatorname{Im}$ or $\operatorname{Im}(\mathrm{Fe})$ film, and the electrocatalytic activity towards the $\mathrm{O}_{2}$ reduction was measured. In the presence of the $\mathrm{Im}$, the measured electrocatalytic current for $\mathrm{O}_{2}$ reduction increased $30 \%$, and the overpotential drastically decreased by almost $100 \mathrm{mV}$, proving that the Im can act as a good support for the electrocatalysts.
\end{abstract}

Keywords: imogolite; Fe-modified imogolite; iron phthalocyanine; modified electrodes; oxygen reduction reaction

\section{Introduction}

Nanoparticles are of great scientific interest because of their physical properties, like large surface-to-volume ratio, strong mechanical resistance and the presence of quantum effects. Because of all of those properties, they have been employed in various research fields, among them electrochemistry. Especially carbonaceous nanomaterials, like carbon nanotubes (CNTs) and graphene, have been extensively incorporated into various electrode architectures to increase the sensitivity of amperometric biosensors and sensors, to enhance the electron transfer from the redox center of proteins and inorganic molecules and to develop biological and inorganic anodes and cathodes [1-4]. The extremely high conductivity of those nanoparticles and their compatibility with both organic and inorganic molecules have made them excellent candidates for the development of electrochemical devices [2]. However, CNTs present the disadvantages of being hard to synthesize, separate, purify 
and modify, and they are expensive [5]. The high cost prohibits the massive use of CNTs for commercial products [1]. An interesting type of nanoparticle that could solve those problems is the imogolites $(\mathrm{Im})$, which are naturally-occurring nanomaterials, with a structure similar to that of single-walled carbon nanotubes [6-8]. Im can be obtained from glassy volcanic ash soils and can also be synthesized [9-11]. They have the general formula $(\mathrm{OH})_{3} \mathrm{Al}_{2} \mathrm{O}_{3} \mathrm{SiOH}$, and tubes with various structures can be produced $[8,12,13]$. Moreover, different modifications can be applied to the inside and/or the outside of the tubes [10,14-16]. In nature, Im can be found as hollow nanotubes with an outer diameter of $\sim 2.5 \mathrm{~nm}$, an inner diameter of less than $1 \mathrm{~nm}$ and lengths between several hundred nanometers to one micrometer [11,17-19]. Im are regarded as a semiconductor when they are exposed to air [20]. However, it is known that Im react with phosphonates and other groups, like carboxylates [17], forming covalent bonds and giving products with different optical and electrical properties, which can be regarded as conductive $[18,19,21-24]$. In the present work, imogolite (Im) and Fe-modified imogolite $(\operatorname{Im}(\mathrm{Fe}))$ nanoparticles were synthesized and characterized by FTIR spectroscopy, powder $X$-ray diffraction (XRD), isoelectric point (IEP) and transmission and scanning electron microscopy (TEM, SEM). Moreover, the possibility of employing them as an electrochemical support was studied. Therefore, highly-oriented basal plane graphite electrodes (GE) modified with $\operatorname{Im}$ and $\operatorname{Im}(\mathrm{Fe})$ were characterized. The electrochemical window and potential limits of the modified electrodes immersed in phosphate buffer at $\mathrm{pH} 7$ are studied by means of cyclic voltammetry in the presence of oxygen and in oxygen free buffer. To prove that $\operatorname{Im}$ and $\operatorname{Im}(\mathrm{Fe})$ can be employed as nano-supports for electrochemical devices, the $\operatorname{Im}$ and $\operatorname{Im}(\mathrm{Fe})$ nanoparticles were further modified with iron phthalocyanine ( $\mathrm{FePc}$ (see the schematic representation in Figure 1), and the efficiency of the electrochemical system for the oxygen reduction reaction (ORR) was studied [25]. To the best of our knowledge, this is the first time that $\operatorname{Im}$ and $\operatorname{Im}(\mathrm{Fe})$ have been employed as support nanomaterial for electrochemical devices.

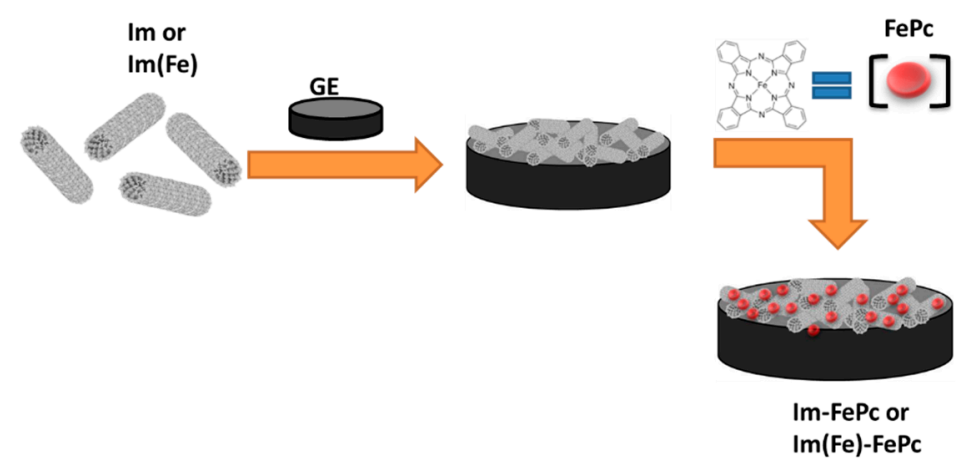

Figure 1. Scheme of the graphite electrode (GE) modified with imogolites ( $\operatorname{Im})$ or $\operatorname{Im}(\mathrm{Fe})$ and then with $\operatorname{Im}$ or $\operatorname{Im}(\mathrm{Fe})$ and FePc.

\section{Materials and Methods}

All reagents and solvents were of analytical grade, obtained from Sigma-Aldrich (St. Louis, MO, USA) and used as received. For all of the experiments, deionized and double-distilled water was used. Im was prepared according to the procedure described by Arancibia-Miranda et al. [9,10]. Briefly, tetraethyl orthosilicate (TEOS) was added to a $5 \mathrm{mM}$ aqueous solution of $\mathrm{AlCl}_{3}$ until an Al:Si ratio of 2:1 was reached. Then, a $0.1 \mathrm{M} \mathrm{NaOH}$ solution was added at a rate of $1.0 \mathrm{~mL} \cdot \mathrm{min}^{-1}$ until an Al:Si:OH ratio of 2:1:4 was obtained. The mixture was stirred during $60 \mathrm{~min}$ and then heated at $368 \mathrm{~K}$ for 5 days. Once the aging process was completed, the resultant mixture was allowed to cool down to ambient temperature. A $0.1 \mathrm{M} \mathrm{NH}_{4} \mathrm{OH}$ solution was added, stirring vigorously, until a $\mathrm{pH}$ of about 8.0 was reached. The solid was concentrated by centrifuging the suspension at $9000 \mathrm{rpm}$ for $30 \mathrm{~min}$ and was washed with double distilled water until an electric conductivity lower than $0.78 \mathrm{~S} \cdot \mathrm{m}^{-1}$ was reached.

To prepare the $\operatorname{Im}(\mathrm{Fe})$, tetraethyl orthosilicate (TEOS) was added to a $150 \mathrm{mM}$ aqueous solution containing a mixture of $\mathrm{FeCl}_{3}$ and $\mathrm{AlCl}_{3}$ in a molar ratio of $\mathrm{Fe} /(\mathrm{Al}+\mathrm{Fe})=0.05$ [11]. The mixture was 
stirred for $1.5 \mathrm{~h}$, and the gel-like precursor was obtained by slowly adding $0.1 \mathrm{M} \mathrm{NaOH}$ aqueous solution until a $\mathrm{pH}=5.5$ was reached. The salt-free precursor obtained after washing was dispersed in $2 \mathrm{~L}$ of double-distilled water. After adding $40 \mathrm{~mL}$ of $0.1 \mathrm{M} \mathrm{HCl}$ and stirring for several hours, the solution was kept at $373 \mathrm{~K}$ under sealing for $40 \mathrm{~h}$. Both, the $\operatorname{Im}$ and $\operatorname{Im}(\mathrm{Fe})$ were dried at $373 \mathrm{~K}$.

The isoelectric point (IEP) was determined through electrophoretic migration (EM) measurements, which were carried out with a Zetameter System 4.0 (Staunton, VA, USA). The imogolite samples $\left(\sim 100 \mathrm{mg}\right.$ ) were suspended in $200 \mathrm{~mL}$ of $1.0 \mathrm{mM} \mathrm{KNO}_{3}$ aqueous solution; the EM was determined as a function of $\mathrm{pH}$. From the plot of EM versus $\mathrm{pH}$, the IEP was determined as the $\mathrm{pH}$ value at $\mathrm{EM}=0$.

Transmission electron microscopy (TEM): TEM samples were prepared by dipping Lacey-CarbonFormvar-coated copper grids 300 Square, Pelco, (Redding, CA, USA) in dilute suspensions of Im or $\operatorname{Im}(\mathrm{Fe})$ and drying them in air before observation. Specimens were examined in an LEO 910 TEM (Zeiss, Oberkochen, Germany) operating at $120 \mathrm{kV}$.

$\mathrm{X}$-ray diffraction $(\mathrm{XRD})$ : XRD analyses were carried out using oriented aggregate preparations obtained by drying water suspensions of the samples on glass slides. The samples were scanned from $3^{\circ}$ to $70^{\circ} 2 \theta$ using a step size of $0.02^{\circ} 2 \theta$ and scanning for $1.0 \mathrm{~s}$ at each step. The $X$-ray patterns were collected using $\mathrm{CuK} \alpha$ radiation from a Philips X'Pert diffractometer generator (Philips, Eindhoven, The Netherlands) and a theta/theta goniometer equipped with $1.5^{\circ}$ divergence slit, a $0.2^{\circ}$ receiving slit, a graphite diffracted-beam monochromator and a scintillation counter $[9,10]$.

SEM images of GE and GE modified with $\operatorname{Im}$ and $\operatorname{Im}(\mathrm{Fe})$ were recorded with a field emission scanning electron microscope (FE-SEM) Model 200 Nova FEI Company (Hillsboro, OR, USA). This equipment includes an energy dispersive X-ray detector Oxford INCA X-sight model (Oxfordshire, UK). The operative conditions were performed at low vacuum conditions, Helix detector at 10 to $18 \mathrm{kV}$. SEM images are shown in the Supporting Information file.

Fourier transform infrared spectroscopy (FTIR): FTIR spectra were obtained on a Tensor 27 Bruker spectrometer (Billerica, MA, USA) for both compounds by pressing $3 \mathrm{mg}$ of dry sample in a spectral grade $\mathrm{KBr}$ matrix. The spectra were scanned 32 times at a resolution of $2 \mathrm{~cm}^{-1}[9,10]$.

Specific surface area (SSA): The SSA, and the micropore and mesopore volumes and diameter were determined from the nitrogen adsorption-desorption isotherms on a Micromeritics Model ASAP 2010 (Norcross, GA, USA) and in a Carlo Erba Sorptmatic 900 (Cornaredo, Italy) by the static volumetric method. Samples of $0.5 \mathrm{~g}$ were degassed at $483 \mathrm{~K}$ for $24 \mathrm{~h}$, with a residual vacuum of $0.532 \mathrm{~Pa}$. The SSA was calculated from the nitrogen adsorption isotherm at $77 \mathrm{~K}$ by the Brunauer, Emmett and Teller (BET) method through multipoint calculation by choosing the result given by the best linear fit in the 0.1 to $0.2 \mathrm{P} / \mathrm{P}^{\circ}$ range $[26,27]$; the micropores' volume was calculated from the nitrogen adsorption at $77 \mathrm{~K}$ by the t-plot method and derived by applying the $\alpha_{\mathrm{s}}$ method; the volume and diameter of the mesopores were calculated from the adsorption/desorption nitrogen isotherm by the Barrett, Joyner and Halenda (BJH) method [26]. All samples were analyzed in triplicate.

For the electrochemical experiments, all of the solutions were purged with ultrapure nitrogen $\left(\mathrm{N}_{2}\right)$ or ultrapure oxygen $\left(\mathrm{O}_{2}\right)$ during $30 \mathrm{~min}$ prior to each measurement, depending on the experiment. Cyclic voltammetry was conducted between -0.8 and $0.8 \mathrm{~V}$ at 50 and at $5 \mathrm{mV} / \mathrm{s}$. The working electrode was a highly-oriented basal plane pyrolytic graphite electrode (GE) (Pine Research Instrumentation, Durham, NC, USA) with a geometric area of $0.196 \mathrm{~cm}^{2}$ mounted on a Teflon support. The GE electrode was polished before each experiment with 1200 grit emery paper followed by ultrasonic treatment in purified water during $2 \mathrm{~min}$ [3].

The modification of the GE was performed by placing first $20 \mu \mathrm{L}$ of $1 \mathrm{mg} / \mathrm{mL}$ nanoparticle suspension (i.e., $\operatorname{Im}$ or $\operatorname{Im}(\mathrm{Fe})$ ) on the electrode and letting it dry to obtain a consistent and stable white-transparent film of nanoparticles, which was visible on the top of the GE (i.e., Im-GE or $\operatorname{Im}(\mathrm{Fe})-\mathrm{GE})$. To obtain electrodes modified with FePc, the previously-described Im-GE and $\operatorname{Im}(\mathrm{Fe})-\mathrm{GE}$ were further modified by placing $20 \mu \mathrm{L}$ of FePc solution until it dried. DMF was used to prepare $1 \mathrm{mM}$ solutions of FePc. 
A saturated calomel electrode (SCE) (Metrohm, Herisau, Switzerland) was used as the reference electrode, and the auxiliary electrode was a platinum (99.99\%, Sigma-Aldrich) spiral wire with an exposed area of $10 \mathrm{~cm}^{2}$. The cyclic voltammetry experiments were performed with a Bio-Analytical Systems, BASI-Epsilon potentiostat (West Lafayette, IN, USA) using a conventional three-electrode electrochemical cell. A $0.1 \mathrm{M}$ phosphate-buffer solution at $\mathrm{pH} 7$ was employed during all of the experiments.

\section{Discussion and Results}

The surface of Im and Im(Fe) was characterized by FTIR, XRD, TEM and SEM. The features of the spectra indicate that both nanofibers have similar surface characteristics, with about $313 \pm 15$ and $303 \pm 15 \mathrm{~m}^{2} / \mathrm{g}$ surface areas for $\operatorname{Im}$ and $\operatorname{Im}(\mathrm{Fe})$, respectively. Additionally, the pore volume $\left(0.25 \pm 0.01 \mathrm{~cm}^{3} / \mathrm{g}\right)$ and the micropore volume $\left(0.02 \pm 0.01 \mathrm{~cm}^{3} / \mathrm{g}\right)$ have the same values for both imogolites. The FTIR spectra of $\operatorname{Im}$ and $\operatorname{Im}(\mathrm{Fe})$ are shown in Figure 2A. Both samples show the characteristic signals of Im at 487, 537, 723, 990 and $939 \mathrm{~cm}^{-1}$, belonging to the Si-O stretching vibrations, which are specific for tubular structures. For the $\operatorname{Im}(\mathrm{Fe})$, the band width is greater compared to the Im, as a consequence of the larger size and weight of the Fe atom compared to the Al atom. The XRD patterns of Im and $\operatorname{Im}(\mathrm{Fe})$ exhibit four diffuse bands at 21.0, 12.0, 3.4 and $2.2 \AA$ (Figure 2B). These reflections have been reported in the literature as characteristic for $\operatorname{Im}[9,28,29]$. The IEP vs. $\mathrm{pH}$ curves are shown in Figure 3, with $\operatorname{IEP}_{\operatorname{Im}}=9.8 \pm 0.2$ and $\operatorname{IEP}_{\operatorname{Im}(\mathrm{Fe})}=7.3 \pm 0.2$. These results indicate that the synthesis of imogolite in the presence of $\mathrm{Fe}^{3+}$ results in a shifting of IEP values to more acidic $\mathrm{pH}$ values, resulting in differences in the magnitude of the surface charge from about $\mathrm{pH}=6$, and in the sign of the surface charge from $\mathrm{pH}$ over 7.3, consequently affecting the electrostatic interaction with charged species present in the solution.
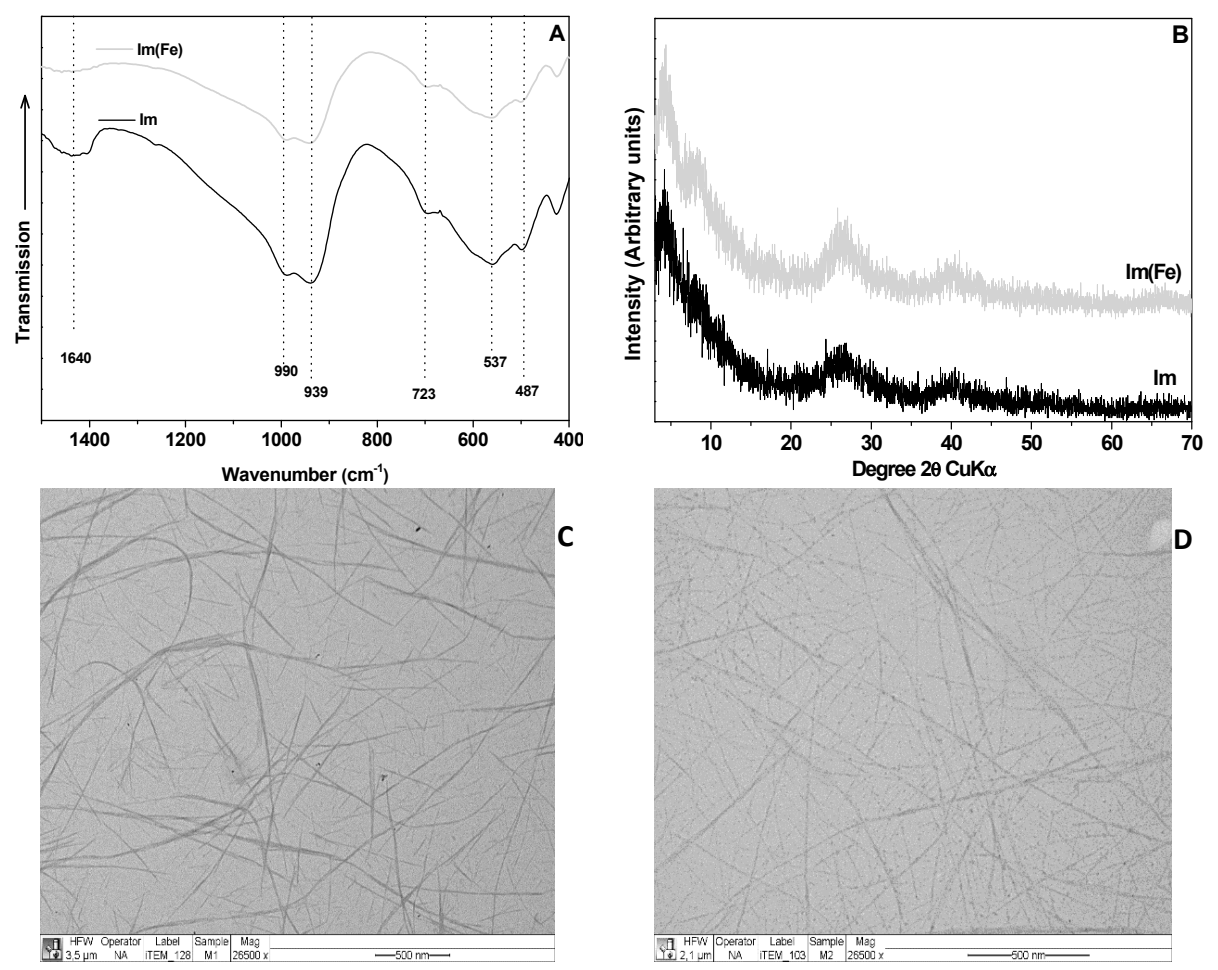

Figure 2. (A) Fourier transform infrared spectroscopy (FTIR) spectra of $\operatorname{Im}$ and $\operatorname{Im}(\mathrm{Fe})$; (B) X-ray diffraction (XRD) pattern of $\operatorname{Im}$ and $\operatorname{Im}(\mathrm{Fe})$; (C) Transmission electron microscopy (TEM) micrograph of Im; (D) TEM micrograph of $\operatorname{Im}(\mathrm{Fe})$. 


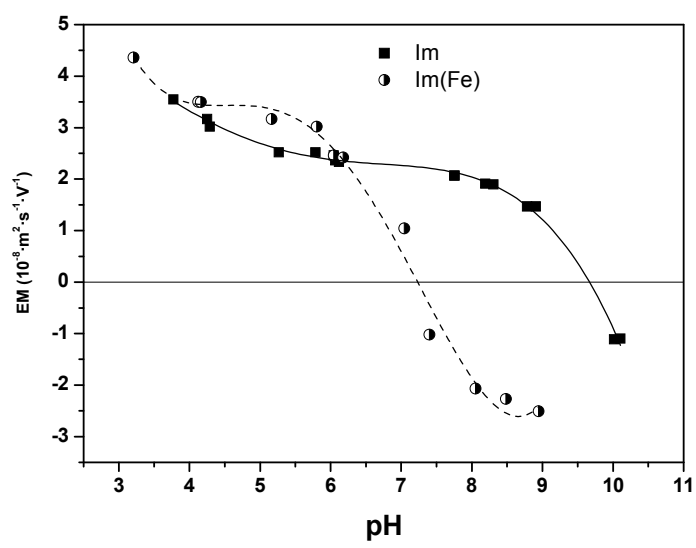

Figure 3. Electrophoretic migration vs. $\mathrm{pH}$ curves for $\operatorname{Im}$ (squares) and $\operatorname{Im}(\mathrm{Fe})$ (circles). EM, electrophoretic migration.

The observation of the solid Im samples (Figure 2C) showed that the spatial distribution of the Im nanotubes resembles a spider web. The average dimensions of the Im exceed $500 \mathrm{~nm}$ in length. The micrograph of $\operatorname{Im}(\mathrm{Fe})$ is shown in Figure 2D.

Nanotube materials, 300 to $500 \mathrm{~nm}$ in length, are seen in these micrographs, and their fibrous morphology is similar to that of Im; nevertheless, the average length is half that of the Im. According to the analysis, the average diameter of $\mathrm{Im}$ is estimated at 2.0 to $2.1 \mathrm{~nm}$, while the average diameter for $\operatorname{Im}(\mathrm{Fe})$ is estimated at 2.4 to $2.6 \mathrm{~nm}$. The $\operatorname{Im}(\mathrm{Fe})$ presents also a small amount of spherical structure, which is probably due to the formation of allophane or Fe oxide. SEM images of bare GE (Figure S1) and GE modified with $\operatorname{Im}$ (Figure S2) and $\operatorname{Im}(\mathrm{Fe}$ ) (Figure S3) are shown in the Supporting Information file. Energy-dispersive X-ray spectroscopy analysis (EDX) shows the presence of $\mathrm{Al}$ and $\mathrm{Si}$ for the $\mathrm{Im}$ (Figure S2c), as well as some precursors employed for the synthesis (e.g., $\mathrm{Na}, \mathrm{K}, \mathrm{Ca}$ ). For the $\operatorname{Im}(\mathrm{Fe})$, the presence of $\mathrm{Fe}$ is evident (Figure $\mathrm{S} 3 \mathrm{~b}, \mathrm{c}$ ).

To prove that $\operatorname{Im}$ and $\operatorname{Im}(\mathrm{Fe})$ could be used as nanoparticles for electrochemical devices, GE were modified with $20 \mu \mathrm{L}$ of $1 \mathrm{mg} / \mathrm{mL}$ water solutions of the respective nanoparticles. The modification of the GE was obtained by physical adsorption of the nanoparticles and is schematized in Figure 1 . After the modification, a stable white-transparent film could be noticed on the top of the GE. The cyclic voltammetry in the absence and in the presence of oxygen for a bare GE and GE modified with Im and $\operatorname{Im}(\mathrm{Fe})$ is presented in Figure 4A.
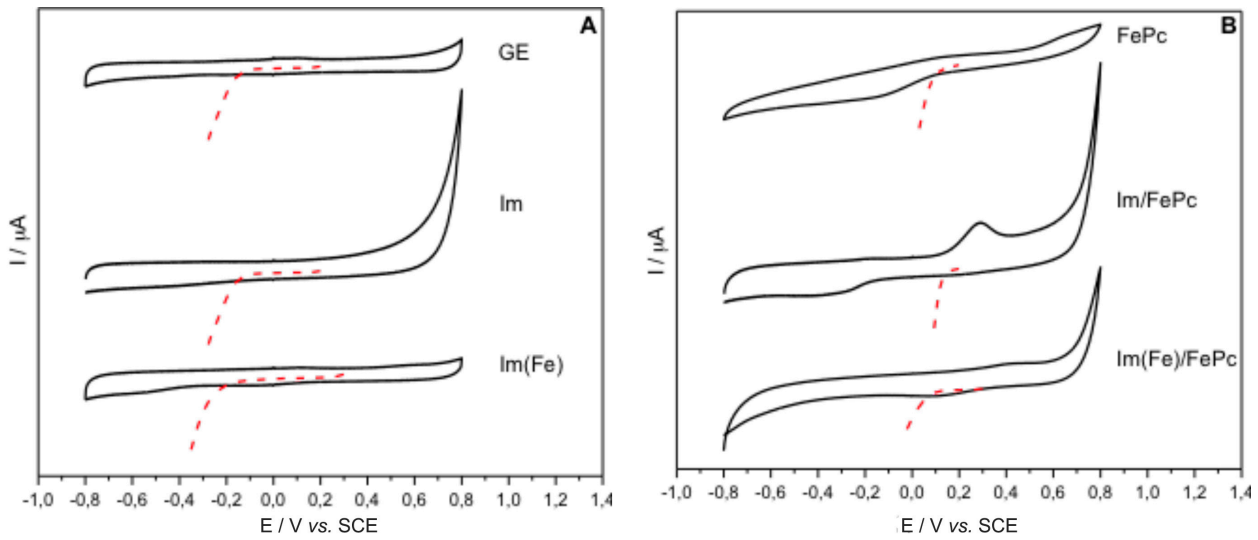

Figure 4. (A) Cyclic voltammetry and polarization curves for the oxygen reduction reaction (ORR) $\left(\mathrm{O}_{2}\right.$ saturated conditions, dotted red line) of the graphite electrodes (GE) and GE modified with Im and with $\operatorname{Im}(\mathrm{Fe})$; (B) Cyclic voltammetry and polarization curves $\left(\mathrm{O}_{2}\right.$ saturated conditions, dotted red line) of the GE modified with FePc, Im-FePc and Im(Fe)-FePc. SCE, saturated calomel electrode. 
Each cyclic voltammogram was repeated at least five times (with intervals of $30 \mathrm{~m}$ for depleting the $\mathrm{O}_{2}$ content with $\mathrm{N}_{2}$ or to saturate with $\mathrm{O}_{2}$ ) to guarantee the stability of the electrode, and at least five electrodes for each experiment were measured to guarantee the reproducibility of the experiments. Current density values varied from one electrode to another up to $10 \%$ of the total measured current. This difference was expected because of the various steps that are necessary for the preparation. In Figure 4A, the cyclic voltammograms for each kind of electrode modification (i.e., bare GE, GE modified with Im and GE modified with $\mathrm{Im}(\mathrm{Fe})$ ) in the absence of $\mathrm{O}_{2}$ and in the presence of $\mathrm{O}_{2}$ (red curve) are presented. The results show that the electrodes modified with only $\operatorname{Im}$ and $\operatorname{Im}(\mathrm{Fe})$ do not present redox processes (Figure 4A) in the electrochemical potential window that ranges from -0.8 to $0.8 \mathrm{~V}$ ws. SCE. Extended X-ray Absorption Fine Structure studies (EXAFS) show that the Fe present in the $\operatorname{Im}(\mathrm{Fe})$ is octahedrally-coordinated, and a change in the oxidation state of the $\mathrm{Fe}^{2+}$ used as the precursor to $\mathrm{Fe}^{3+}$ occurs [30,31]. The magnitude of Fe signals in the EDX spectrum (Figure S3c) shows the low replacement of the $\mathrm{Al}$ atoms for $\mathrm{Fe}$, which is consistent with the low amount allowed to maintain the nanotube structure [30]. The absence of redox processes in the presence of $\operatorname{Im}(\mathrm{Fe})$ is in accordance with the limited number of Fe atoms that can replace the Al present in the Im [11,30,31]. In the presence of imogolites, the electrode charging/discharging current (i.e., capacitive current) resembles the values that are double with respect to the unmodified GE. This is evidence of the increased active surface area. Similar results were obtained when GE were modified with CNTs [32-34]. Polarization curves in the presence of oxygen (Figure 4A) were recorded for the GE and for the modified GE. As we can notice from Figure $4 \mathrm{~A}$, in the presence of $\operatorname{Im}$ and $\operatorname{Im}(\mathrm{Fe})$, the overpotential for the ORR slightly decreases $(\approx 50 \mathrm{mV}$ towards more positive redox potentials with the ORR catalytic wave starting at $-100 \mathrm{mV}$ instead of $-150 \mathrm{mV}$ vs. SCE) in the presence of Im and $\operatorname{Im}(\mathrm{Fe})$. This effect can be explained by the difference of the exposed electro-active surface among the unmodified GE, the Im and $\operatorname{Im}(\mathrm{Fe})$-modified GE. The high surface area of the $\operatorname{Im}$ and $\operatorname{Im}(\mathrm{Fe})$ could provide a more advantageous environment for the ORR. In fact, imogolites have been proposed as catalysts for various reactions before [11,35]. When GE are modified with only FePc, or with Im and $\mathrm{FePc}$, or with $\operatorname{Im}(\mathrm{Fe})$ and FePc to form, respectively, $\mathrm{Im} / \mathrm{FePC}$ and $\operatorname{Im}(\mathrm{Fe}) / \mathrm{FePC}$, oxidation and reduction processes are noticeable at a potential around $200 \mathrm{mV}$ for the FePC modified GE and at potentials of around $250 \mathrm{mV}$ vs. SCE, when the imogolites are also present (Figure 4B and Figure S4). Those redox processes are attributable to the $\mathrm{Fe}^{3+} / \mathrm{Fe}^{2+}$ redox couple of the FePC. Furthermore, in the presence of the imogolites, the oxidation and reduction peaks have larger areas. While an increased area for the oxidation and reduction peaks was expected because of the higher active surface area due to the presence of the imogolites and, therefore, a higher concentration of the FePc on the top of the electrode, the displacement towards more oxidative potentials is a sign that more energy is required for the oxidation of the FePC, which is present on the top of the imogolites. Probably, the interactions of the imogolites with the FePC are rather repulsive, which could cause the increment of the formal redox potential of the FePC. Furthermore the presence of the imogolites could causes the formation of stacks which would require more energy to undergo the oxidation/reduction process and, therefore, the increment of the formal potential of the redox couple $\mathrm{Fe}^{3+} / \mathrm{Fe}^{2+}$ present in the FePc if compared to the formal potential of monolayers of FePc, which are present on the top of GE. Corresponding to an increased potential for the oxidation/reduction of the $\mathrm{Fe}^{3+} / \mathrm{Fe}^{2+}$ redox couple, also the potential for the ORR increased from $\approx 100 \mathrm{mV}$ vs. SCE for the FePc GE system to $\approx 190 \mathrm{mV}$ for the $\mathrm{Im} / \mathrm{FePc}$ system and to $\approx 150 \mathrm{mV}$ for the $\mathrm{Im}(\mathrm{Fe}) / \mathrm{FePC}$. Indeed when imogolites are present, the overpotential for the ORR decreased by almost $100 \mathrm{mV}$. This is in agreement with the increased potential for the reduction of the $\mathrm{Fe}^{3+} / \mathrm{Fe}^{2+}$ redox couple. In fact, the latest research works of the ORR at phthalocyanine-modified electrodes suggest that closer the redox potential of the catalyst to the formal potential of the reaction to catalyze, the better the catalyst [36-39]. When the Im are combined with FePc, not only the overpotential for the ORR decreased, but also the catalytic current increased from $158 \mu \mathrm{A} / \mathrm{cm}^{2}$ for the FePc immobilized on GE to $226 \mu \mathrm{A} / \mathrm{cm}^{2}$ for Im $/ \mathrm{FePc}$ and to $185 \mu \mathrm{A} / \mathrm{cm}^{2}$ for the $\operatorname{Im}(\mathrm{Fe}) / \mathrm{FePc}$ (in Figure S4, the entire catalytic curve is shown), proving again that the imogolites 
provide a large surface area, allowing a larger amount of active sites of FePc to concentrate on the top of the modified electrode surface. The Im proved to be a better support than the $\operatorname{Im}(\mathrm{Fe})$. Probably, the presence of Fe results in defects in the structure of the nanoparticles or the presence of Fe in the Im structure collides with the Fe of the FePc. Anyway, further experiments are necessary to explain the behavior of FePc on the top of Im-modified electrodes and also to understand the potential of imogolites in electrochemistry.

\section{Conclusions}

Im and $\operatorname{Im}(\mathrm{Fe})$ were characterized by FTIR, XRD, TEM and SEM and were evaluated by means of cyclic voltammetry and polarization curves for their employment in the development of electrochemical devices. Characterization of $\operatorname{Im}$ and $\operatorname{Im}(\mathrm{Fe})$ revealed that both nanoparticles have similar features: $\approx 300 \mathrm{~m}^{2} / \mathrm{g}$ surface area, pore volume of $\approx 0.25 \mathrm{~cm}^{3} / \mathrm{g}$, average length of $500 \mathrm{~nm}$ and average diameter of $\approx 0.2 \mathrm{~nm}$. Electrodes modified with $\operatorname{Im}$ and $\operatorname{Im}(\mathrm{Fe})$ showed an increased electrochemically-active surface area (increased capacitive current) and the absence of redox processes in the electrochemical window that ranges from -0.8 to $0.8 \mathrm{~V} v$ s. SCE. When GE were modified with $\operatorname{Im}$ or $\operatorname{Im}(\mathrm{Fe})$ and $\mathrm{FePc}$, a redox peak for the oxidation-reduction of the $\mathrm{Fe}^{3+} / \mathrm{Fe}^{2+}$ redox couple was registered. The registered peak had a larger area than when FePc is absorbed on bare GE, proving that a large amount of FePc over the Im is absorbed and active. Furthermore, a displacement of the peak of $\approx 50 \mathrm{mV}$ towards the oxidative region was noticed (from -150 to $-100 \mathrm{mV}$ vs. SCE). The modification with Im and FePc generated an increment of $30 \%$ in the current density for the ORR $\left(\approx 220 \mu \mathrm{A} / \mathrm{cm}^{2}\right)$, while with the $\operatorname{Im}(\mathrm{Fe}) / \mathrm{FePc}$, only an increment of $15 \%$ was obtained $\left(\approx 180 \mu \mathrm{A} / \mathrm{cm}^{2}\right)$.

Supplementary Materials: The following are available online at http://www.mdpi.com/2079-4991/6/2/28/s1. Figure S1: (a) Scanning electron microscopy (SEM) image and (b) energy-dispersive X-ray spectroscopy (EDX) spectrum of the graphite electrodes (GE) basal plane. Figure S2: (a) SEM image, (b) layered energy dispersed spectroscopy (EDS) and (c) EDX spectrum of GE modified with Im. Figure S3: (a) SEM image, (b) layered EDS and (c) EDX spectrum of GE modified with $\mathrm{Im}(\mathrm{Fe})$. Figure S4: (a) Cyclic voltammetry and polarization curves for the oxygen reduction reaction (ORR) $\left(\mathrm{O}_{2}\right.$ saturated conditions, red line) of the GE and GE modified with Im and with $\operatorname{Im}(\mathrm{Fe})$; (b) cyclic voltammetry and polarization curves $\left(\mathrm{O}_{2}\right.$ saturated conditions, red line) of the GE modified with $\mathrm{FePc}$, Im/FePc and $\operatorname{Im}(\mathrm{Fe}) / \mathrm{FePc}$.

Acknowledgments: This study was supported by DICYT ASOCIATIVO 021342TG_DAS, FONDECYT INICIACIÓN 11130167, FONDECYT INICIACIÓN 11130157, MECESUP USA1298, Basal Funding for Scientific and Technological Centers under Project FB0807.

Author Contributions: Carmen Castro and Nicolas Arancibia-Miranda performed all experimental work and data collections. Nicolas Arancibia-Miranda and Federico Tasca supervised the experimental work. Nicolas Arancibia-Miranda, Cristina Acuña-Rougier, Mauricio Escudey and Federico Tasca wrote the manuscript.

Conflicts of Interest: The authors declare no conflict of interest.

\section{References}

1. Andrews, R.; Jacques, D.; Qian, D.L.; Rantell, T. Multiwall carbon nanotubes: Synthesis and application. Acc. Chem. Res. 2002, 35, 1008-1017. [CrossRef]

2. Pumera, M.; Ambrosi, A.; Bonanni, A.; Chng, E.L.K.; Poh, H.L. Graphene for electrochemical sensing and biosensing. TrAC-Trend Anal. Chem. 2010, 29, 954-965. [CrossRef]

3. Tasca, F.; Gorton, L.; Wagner, J.B.; Nöll, G. Increasing amperometric biosensor sensitivity by length fractionated single-walled carbon nanotubes. Biosens. Bioelectron. 2008, 24, 272-278. [CrossRef] [PubMed]

4. Tasca, F.; Harreither, W.; Ludwig, R.; Gooding, J.J.; Gorton, L. Cellobiose Dehydrogenase Aryl Diazoniunn Modified Single Walled Carbon Nanotubes: Enhanced Direct Electron Transfer through a Positively Charged Surface. Anal. Chem. 2011, 83, 3042-3049. [CrossRef] [PubMed]

5. Paradise, M.; Goswami, T. Carbon nanotubes_Production and industrial applications. Mater. Des. 2007, 28, 1477-1489. [CrossRef]

6. Bursill, L.A.; Peng, J.L.; Bourgeois, L.N. Imogolite: An aluminosilicate nanotube material. Philos. Mag. A 2000, 80, 105-117. [CrossRef] 
7. Tamura, K.; Kawamura, K. Molecular dynamics modeling of tubular aluminum silicate: Imogolite. J. Phys. Chem. B 2002, 106, 271-278. [CrossRef]

8. Mukherjee, S.; Bartlow, V.A.; Nair, S. Phenomenology of the growth of single-walled aluminosilicate and aluminogermanate nanotubes of precise dimensions. Chem. Mater. 2005, 17, 4900-4909. [CrossRef]

9. Arancibia-Miranda, N.; Escudey, M.; Molina, M.; Garcia-Gonzalez, M.T. Use of isoelectric point and pH to evaluate the synthesis of a nanotubular aluminosilicate. J. Non-Cryst. Solids. 2011, 357, 1750-1756. [CrossRef]

10. Arancibia-Miranda, N.; Escudey, M.; Pizarro, C.; Denardin, J.C.; García-González, M.T.; Fabris, J.D.; Charlet, L. Preparation and characterization of a single-walled aluminosilicate nanotube-iron oxide composite: Its applications to removal of aqueous arsenate. Mater. Res. Bull. 2014, 51, 145-152. [CrossRef]

11. Ookawa, M.; Takata, Y.; Suzuki, M.; Inukai, K.; Maekawa, T.; Yamaguchi, T. Oxidation of aromatic hydrocarbons with $\mathrm{H}_{2} \mathrm{O}_{2}$ catalyzed by a nano-scale tubular aluminosilicate, Fe-containing imogolite. Res. Chem. Intermed. 2008, 34, 679-685. [CrossRef]

12. Mukherjee, S.; Kim, K.; Nair, S. Short, highly ordered, single-walled mixed-oxide nanotubes assemble from amorphous nanoparticles. J. Am. Chem. Soc. 2007, 129, 6820-6826. [CrossRef] [PubMed]

13. Konduri, S.; Mukherjee, S.; Nair, S. Controlling nanotube dimensions: Correlation between composition, diameter, and internal energy of single-walled mixed oxide nanotubes. ACS Nano 2007, 1,393-402. [CrossRef] [PubMed]

14. Yucelen, G.I.; Choudhury, R.P.; Vyalikh, A.; Scheler, U.; Beckham, H.W.; Nair, S. Formation of Single-Walled Aluminosilicate Nanotubes from Molecular Precursors and Curved Nanoscale Intermediates. J. Am. Chem. Soc. 2011, 133, 5397-5412. [CrossRef] [PubMed]

15. Yucelen, G.I.; Kang, D.Y.; Guerrero-Ferreira, R.C.; Wright, E.R.; Beckham, H.W.; Nair, S. Shaping Single-Walled Metal Oxide Nanotubes from Precursors of Controlled Curvature. Nano Lett. 2012, 12, 827-832. [CrossRef] [PubMed]

16. Kang, D.Y.; Zang, J.; Jones, C.W.; Nair, S. Single-Walled Aluminosilicate Nanotubes with Organic-Modified Interiors. J. Phys. Chem. 2011, 115, 7676-7685. [CrossRef]

17. Yamamoto, K.; Otsuka, H.; Takahara, A.; Wada, S.I. Preparation of a novel (polymer/inorganic nanofiber) composite through surface modification of natural aluminosilicate nanofiber. J. Adhes. 2002, 78, 591-602. [CrossRef]

18. Yamamoto, K.; Otsuka, H.; Wada, S.I.; Sohn, D.; Takahara, A. Preparation and properties of poly(methyl methacrylate)/imogolite hybrid via surface modification using phosphoric acid ester. Polymer 2005, 46, 12386-12392. [CrossRef]

19. Yamamoto, K.; Otsuka, H.; Takahara, A. Preparation of novel polymer hybrids from imogolite nanofiber. Polym. J. 2007, 39, 1-15. [CrossRef]

20. Guimaraes, L.; Enyashin, A.N.; Frenzel, J.; Heine, T.; Duarte, H.A.; Seifert, G. Imogolite nanotubes: Stability, electronic, and mechanical properties. ACS Nano 2007, 1, 362-368. [CrossRef] [PubMed]

21. Yamamoto, K.; Otsuka, H.; Wada, S.; Takahara, A. Surface modification of aluminosilicate nanofiber "imogolite". Chem. Lett. 2001, 30, 1162-1173. [CrossRef]

22. Yah, W.O.; Yamamoto, K.; Jiravanichanun, N.; Otsuka, H.; Takahara, A. Imogolite Reinforced Nanocomposites: Multifaceted Green Materials. Materials 2010, 3, 1709-1745. [CrossRef]

23. Yamamoto, K.; Otsuka, H.; Wada, S.I.; Sohn, D.; Takahara, A. Transparent polymer nanohybrid prepared by in situ synthesis of aluminosilicate nanofibers in poly(vinyl alcohol) solution. Soft Matter 2005, 1, 372-377. [CrossRef]

24. Kuroda, Y.; Kuroda, K. Layer-by-layer assembly of imogolite nanotubes and polyelectrolytes into core-shell particles and their conversion to hierarchically porous spheres. Sci. Technol. Adv. Mat. 2008, 9. [CrossRef]

25. Ben Liew, K.; Daud, W.R.W.; Ghasemi, M.; Leong, J.X.; Lim, W.S.; Ismail, M. Non-Pt catalyst as oxygen reduction reaction in microbial fuel cells: A review. Int. J. Hydrog. Energy 2014, 39, 4870-4883. [CrossRef]

26. Bonelli, B.; Bottero, I.; Ballarini, N.; Passeri, S.; Cavani, F.; Garrone, E. IR spectroscopic and catalytic characterization of the acidity of imogolite-based systems. J. Catal. 2009, 264, 15-30. [CrossRef]

27. Arancibia-Miranda, N.; Escudey, M.; Molina, M.; García-González, M. Kinetic and Surface Study of Single-Walled Aluminosilicate Nanotubes and Their Precursors. Nanomaterials 2013, 3, 126-140. [CrossRef]

28. Cradwick, P.D.G.; Farmer, V.C.; Russell, J.D.; Masson, C.R.; Wada, K.; Yoshinaga, N. Imogolite, a Hydrated Aluminium Silicate of Tubular Structure. Nature-Phys. Sci. 1972, 240, 187-199. [CrossRef] 
29. Levard, C.; Masion, A.; Rose, J.; Doelsch, E.; Borschneck, D.; Dominici, C.; Ziarelli, F.; Bottero, J.Y. Synthesis of Imogolite Fibers from Decimolar Concentration at Low Temperature and Ambient Pressure: A Promising Route for Inexpensive Nanotubes. J. Am. Chem. Soc. 2009, 131, 17080-17089. [CrossRef] [PubMed]

30. Shafia, E.; Esposito, S.; Manzoli, M.; Chiesa, M.; Tiberto, P.; Barrera, G.; Menard, G.; Allia, P. Al/Fe isomorphic substitution versus $\mathrm{Fe}_{2} \mathrm{O}_{3}$ clusters formation in Fe-doped aluminosilicate nanotubes (imogolite). J. Nanopart Res. 2015, 17, 1-14. [CrossRef]

31. Avellan, A.; Levard, C.; Kumar, N.; Rose, J.; Olivi, L.; Thill, A.; Chaurand, P.; Borschneck, D.; Maison, A. Structural incorporation of iron into Ge-imogolite nanotubes: A promising step for innovative nanomaterials. RSC Adv. 2014, 4, 49827-49830. [CrossRef]

32. Favero, G.; Fusco, G.; Mazzei, F.; Tasca, F.; Antiochia, R. Electrochemical Characterization of Graphene and MWCNTs Screen-Printed Electrodes Modified with AuNPs for Laccase Biosensor Development. Nanomaterials 2015, 5, 1995-2006. [CrossRef]

33. Tasca, F.; Gorton, L.; Harreither, W.; Haltrich, D.; Ludwig, R.; Noll, G. Highly Efficient and Versatile Anodes for Biofuel Cells Based on Cellobiose Dehydrogenase from Myriococcum thermophilum. J. Phys. Chem. C 2008, 112, 13668-13673. [CrossRef]

34. Tasca, F.; Gorton, L.; Harreither, W.; Haltrich, D.; Ludwig, R.; Noll, G. Direct electron transfer at cellobiose dehydrogenase modified anodes for biofuel cells. J. Phys. Chem. C 2008, 112, 9956-9961. [CrossRef]

35. Imamura, S.; Kokubu, T.; Yamashita, T.; Okamoto, Y.; Kajiwara, K.; Kanai, H. Shape-selective copper-loaded imogolite catalyst. J. Catal. 1996, 160, 137-139. [CrossRef]

36. Tasca, F.; Recio, F.J.; Venegas, R.; Geraldo, D.A.; Sancy, M.; Zagal, J.H. Linear versus volcano correlations for the electrocatalytic oxidation of hydrazine on graphite electrodes modified with MN4 macrocyclic complexes. Electrochim. Acta 2014, 140, 314-319. [CrossRef]

37. Javier Recio, F.; Canete, P.; Tasca, F.; Linares-Flores, C.; Zagal, J.H. Tuning the Fe(II)/(I) formal potential of the $\mathrm{FeN}_{4}$ catalysts adsorbed on graphite electrodes to the reversible potential of the reaction for maximum activity: Hydrazine oxidation. Electrochem. Commun. 2013, 30, 34-37. [CrossRef]

38. Zagal, J.H.; Gulppi, M.A.; Cardenas-Jiron, G. Metal-centered redox chemistry of substituted cobalt phthalocyanines adsorbed on graphite and correlations with MO calculations and Hammett parameters. Electrocatalytic reduction of a disulfide. Polyhedron 2000, 19, 2255-2260. [CrossRef]

39. Bedioui, F.; Griveau, S.; Nyokong, T.; Appleby, A.J.; Caro, C.A.; Gulppi, M.; Ochoa, G.; Zagal, J.H. Tuning the redox properties of metalloporphyrin- and metallophthalocyanine-based molecular electrodes for the highest electrocatalytic activity in the oxidation of thiols. PCCP 2007, 9, 3383-3396. [CrossRef] [PubMed]

(C) 2016 by the authors; licensee MDPI, Basel, Switzerland. This article is an open access article distributed under the terms and conditions of the Creative Commons by Attribution (CC-BY) license (http://creativecommons.org/licenses/by/4.0/). 